\title{
透明硫化钴对电极在染料敏化太阳能电池中的应用
}

\author{
蒋青松 $^{1,2,3}$, 陈若婷 ${ }^{2}$, 李文波 ${ }^{2}$, 程文杰 ${ }^{2}$, 黄业晓 ${ }^{2}$, 胡 光 $^{2}$
}

(淮阴工学院 1. 电子信息工程学院, 江苏省湖泊环境遥感技术工程实验室; 2. 数理学院; 3. 江苏省凹土资源利用 重点实验室, 淮安 223003)

摘 要: 硫化钴纳米材料是一种重点研究的染料敏化太阳能电池对电极材料。本工作以氟掺杂二氧化锡导电玻璃为 基片, 采用反向恒压电沉积法制备透明硫化钴薄膜。实验结果表明: 电镀溶液的 $\mathrm{pH}$ 是硫化钴薄膜表面形貌形成的 关键性因素, 而电沉积圈数可以有效控制硫化钴薄膜的厚度。电化学测试结果表明: 硫化钴薄膜对电极展现出了良 好的电催化活性, 尤其是在电镀溶液 $\mathrm{pH}$ 为 7.2 、电沉积圈数为 12 圈的最佳条件下制备的硫化钴对电极具有大量的 纳米薄片状结构, 有利于增加电催化活性位点, 使得其展现出了比铂电极更加优异的电催化性能。由此电极组装的 染料敏化太阳能电池的能量转换效率达到 $7.26 \%, 10$ 个电池器件的平均效率为 $7.18 \%$, 高于相应铂电极器件的电池 效率(6.94\%)。

关 键 词: 对电极; 硫化钴; 反向恒压电沉积法; 薄片状形貌

中图分类号: TM914 文献标识码: A

\section{Application of Transparent Cobalt Sulfide Counter Electrodes in Dye-sensitized Solar Cells}

\author{
JIANG Qing-Song ${ }^{1,2,3}$, CHEN Ruo-Ting ${ }^{2}$, LI Wen-Bo ${ }^{2}$, CHENG Wen-Jie², HUANG Ye-Xiao², HU Guang ${ }^{2}$ \\ (1. Jiangsu Engineering Laboratory for Lake Environment Remote Sensing Technologies, Faculty of electronic information en- \\ gineering, Huaiyin Institute of Technology, Huai'an 223003, China; 2. Faculty of Mathematics and Physics, Huaiyin Institute of \\ Technology, Huai'an 223003, China; 3. Key Laboratory for Palygorskite Science and Applied Technology of Jiangsu Province, \\ Huaiyin Institute of Technology, Huai’an 223003, China)
}

\begin{abstract}
Cobalt sulfide nanomaterials are considered as important counter electrode materials for dye-sensitized solar cells. A potential reversal electrodeposition technique was applied to fabricate transparent cobalt sulfide film with fluorine-doped tin oxide glass as substrate. The experimental results demonstrate that the surface morphology of cobalt sulfide films is mainly dependent on the $\mathrm{pH}$ value of plating solution. The thickness of cobalt sulfide films can be effectively controlled by electrodeposition cycles. Then, cobalt sulfide films were used as counter electrodes of dye-sensitized solar cells. Electrochemical measurements prove that cobalt sulfide counter electrodes exhibit high electrocatalytic activity. In particular, under electrodeposition condition of pH 7.2 and 12 cycles, cobalt sulfide counter electrode composed of the nanosheet structure exhibits higher electrocatalytic activity than platinum electrode, due to the increase of electrocatalytic active sites. Meanwhile, remarkable photoelectrical conversion efficiency of the dye-sensitized solar cell based on cobalt sulfide counter electrode is up to $7.26 \%$ with an average value of $7.18 \%$ for
\end{abstract}

收稿日期：2017-10-17; 收到修改稿日期：2017-12-09

基金项目: 国家自然科学基金(61704063); 国家级大学生创新创业训练计划项目(201711049004Z); 江苏省凹土资源利用重 点实验室开放课题(HPK201503)

National Natural Science Foundation of China (61704063); National Training Program of Innovation and Entrepreneurship for Undergraduates (201711049004Z); The Foundation of Key Laboratory for Palygorskite Science and Applied Technology of Jiangsu Province (HPK201503)

作者简介: 蒋青松(1987-), 男, 博士研究生, 讲师. E-mail: jiangqingsong05@hyit.edu.cn

通讯作者: 胡 光, 教授. E-mail: huguang@hyit.edu.cn 
ten devices, which is higher than that of the dye-sensitized solar cell equipped with platinum electrode (6.94\%).

Key words: counter electrode; cobalt sulfide; potential reversal electrodeposition technique; sheet morphology

随着全球能源危机日益严重及生存环境恶化, 开发利用可再生、清洁、低成本、高效的新能源是 一项重要举措 ${ }^{[1]}$ 。光伏发电技术是利用太阳能转换 为电能, 获取新能源的有效技术手段之一 ${ }^{[2]}$ 。其中, 染料敏化太阳能电池(DSC)具有生产成本低、原材 料丰富和环境友好等优点, 在便携式电子产品领域 中有着重要应用前景, 得到了广泛关注 ${ }^{[3]}$ 。

在 DSC 构造中, 对电极是必不可少的重要组成 部分, 其主要作用是作为电催化剂将从外电路中收 集的电子转移给氧化态的电解质，实现氧化还原电 对的再生 ${ }^{[4]}$ 。众所周知, 铂电极因具有良好的导电性 和优异的催化活性而用作 DSC 对电极。然而, 铂电 极存在原材料稀缺、成本高等缺点, 不利于 DSC 的 规模化生产 ${ }^{[5]}$ 。因此, 设计制备电催化活性优异、成 本低和稳定性好的非铂对电极材料是 DSC 一个重 要的热点研究方向。

在诸多已探索的非铂对电极材料中, 硫化钴纳 米材料展现出了优异的电催化性能和持久的稳定 性 ${ }^{[6]}$ 。一般情况下, 制备硫化钴纳米材料的方法有水 热法 ${ }^{[6]}$ 、微波辅助加热法 ${ }^{[7]}$ 、电泳沉积法 ${ }^{[8]}$ 、电化学 沉积法 ${ }^{[9]}$ 等。与其他制备方法相比, 电化学沉积法具 有低成本、易操作、环境友好等优势 ${ }^{[10]}$ 。早在 2009 年, 恒电压电沉积法已被用于制备硫化钴薄膜, 且 硫化钴对电极表现出良好的电催化性能 ${ }^{[11]}$ 。为了进 一步优化硫化钴薄膜的电催化活性, 采用动电位电 沉积法制备具有蜂窝状结构的硫化钴薄膜, 其电催 化性能与铂电极相当 ${ }^{[12]}$ 。随着电化学沉积技术快速 发展, 为了有效制备出半透明/透明硫属化合物薄膜 而开发出一种反向恒压电沉积法 ${ }^{[13]}$ 。目前, 采用反 向恒压电沉积法在 $\mathrm{pH} \approx 6$ 的电镀溶液中制备出硫化 钴薄膜, 并作为 DSC 对电极 ${ }^{[14]}$ 。然而, 以此电极组 装的 DSC 能量转换效率有待于进一步提高。通常增 加硫化钴薄膜的比表面积是一种有效的提高硫化钴 对电极电催化性能的方法。而到目前为止, 采用反 向恒压电沉积法制备具有纳米薄片状结构的透明硫 化钴薄膜尚未见报道。

因此, 本研究将以六水合氯化钴为钴源, 硫艮 为硫源, 去离子水为溶剂, 用氨水溶液调节电镀溶 液的 $\mathrm{pH}$, 采用反向恒压电沉积法制备硫化钴(Co-S) 薄膜。研究电镀溶液的 $\mathrm{pH}$ 对 Co-S 薄膜表面形貌的 影响, 从而制备出具有纳米薄片状结构的 Co-S 薄 膜; 探究 Co-S 对电极表面形貌对其电催化性能的
影响, 从而制备出光伏性能优异的 DSC。

\section{1 实验方法}

\section{1 透明硫化钴薄膜的制备}

以氟掺杂二氧化锡(FTO)导电玻璃为基片, 采 用反向恒压电沉积法制备 Co-S 薄膜 ${ }^{[13-14]}$ 。首先配 置电镀溶液, 称取 $0.0595 \mathrm{~g}$ 六水合氯化钴和 $1.9030 \mathrm{~g}$ 硫艮分散于 $50 \mathrm{~mL}$ 去离子水中; 通过滴加氨水溶液 (由 $1 \mathrm{~mL}$ 分析纯氨水稀释在 $10 \mathrm{~mL}$ 去离子水中获得) 调控电镀溶液的 $\mathrm{pH}$ 。其次, 设置电沉积条件, 采用 CHI660E 电化学工作站在室温下完成电沉积过程; 其中以 FTO 导电玻璃为工作电极, 铂丝电极为辅助 电极, $\mathrm{Ag} / \mathrm{AgCl}$ 为参比电极; 阴极电沉积偏压为 $-1.1 \mathrm{~V}$, 设置时间为 $6 \mathrm{~s}$; 阳极电沉积偏压为 $0.1 \mathrm{~V}$, 设置时间为 $24 \mathrm{~s}$ 。最后, 当电沉积一定圈数后, 用去 离子水冲洗 FTO 导电玻璃, 经干燥即可获得 Co-S 薄膜, 并作为对电极。此外, 在 FTO 玻璃上, 采用 射频磁控溅射系统制备铂薄膜作为铂电极。

\subsection{DSC 组装}

以 $3 \mathrm{M}$ 胶带控制薄膜厚度, 采用刮涂法制备二 氧化钛薄膜, 其中二氧化钛的粒径约为 $20 \mathrm{~nm}^{[15]}$ 。 二氧化钛薄膜经热处理冷却至 $60^{\circ} \mathrm{C}$ 时, 迅速放置于 $0.5 \mathrm{mmol} / \mathrm{L} \mathrm{N} 719$ 染料 $\left(\mathrm{C}_{58} \mathrm{H}_{86} \mathrm{O}_{8} \mathrm{~N}_{8} \mathrm{~S}_{2} \mathrm{Ru}\right.$, 二(四丁基 铵)顺式-双(异硫氰基)双( $2,2^{\prime}$ - 联吡啶- $4,4^{\prime}$-二羧酸)钉 (II))的乙醇溶液中, 并在 $60^{\circ} \mathrm{C}$ 下敏化处理 $12 \mathrm{~h}$ 。敏 化结束后, 用乙醇冲洗两次, 经干燥即可获得光阳 极。具有开放式 “三明治” 结构的 DSC 组装过程如 下: 先将光阳极置于遮光板上, 其中遮光板的开孔 面积为 $0.2 \mathrm{~cm}^{2}$; 其次, 将对电极交叉放置于光阳极 上, 且用夹具固定; 最后在两电极间注入液态电解 质(0.30 mol/L 1,2-二甲基-3-丙基咪唑碘, $0.05 \mathrm{~mol} / \mathrm{L} \mathrm{I}_{2}$, $0.5 \mathrm{~mol} / \mathrm{L} \mathrm{LiI}, 0.5 \mathrm{~mol} / \mathrm{L}$ 4-叔丁基吡啶的乙腈溶液)。

\section{3 测试与表征}

采用场发射扫描电子显微镜(SEM, JEOL 7800F) 观察 Co-S 薄膜的表面形貌, 并用能谱仪(EDS)附件 表征 Co-S 薄膜的元素种类、分布情况及含量。采用 透射电子显微镜(TEM, JEOL 2100F)进一步观察 Co-S 薄膜的结构形貌。采用 X 射线光电子能谱仪 (XPS, Thermo SCIENTIFIC ESCALAB 250Xi)表征 Co-S 薄膜表面的元素与价态。采用电化学工作站 (CHI660E)表征 Co-S 对电极的电催化性能。其中, 
利用三电极系统测试对电极的循环伏安 $(\mathrm{CV})$ 曲线 (扫描速率为 $50 \mathrm{mV} / \mathrm{s}$ ); 以相同对电极组建对称电池, 进行电化学阻抗谱(EIS)测试(频率范围是 $0.1 \mathrm{~Hz}$ $1 \mathrm{MHz}$ ，振幅为 $10 \mathrm{mV})$ 。采用光电流密度-电压 $(J-V)$ 曲线表征 DSC 光伏性能, 其中利用光敏二极管校正 模拟光源 (XQ350 500W), 标准太阳光 (AM 1.5)的 光强为 $100 \mathrm{~mW} / \mathrm{cm}^{2}$, 有效光照面积为 $0.2 \mathrm{~cm}^{2}$ 。

\section{2 结果与讨论}

\subsection{Co-S 薄膜表面形貌分析}

一般情况下, 电镀溶液的 $\mathrm{pH}$ 大小对薄膜表面 形貌的形成有着重要影响。因此, 在反向恒压电沉 积过程中, 研究加入不同量氨水溶液对 Co-S 薄膜 表面形貌的影响。在实验中, 经测量氨水溶液加入 量为 $0 、 0.1 、 0.15$ 和 $0.2 \mathrm{~mL}$ 的电镀溶液的 $\mathrm{pH}$ 分别 为 $5.8 、 6.7 、 7.2$ 和 7.6 。在电沉积圈数为 12 圈条件 下制备的 Co-S 薄膜标记为 S-pH5.8、S-pH6.7、 S-pH7.2 和 S-pH7.6。图 1(a) (d) 是 Co-S 薄膜的 SEM 照片。从图 1(a)中可以看出, 样品 S-pH5.8 呈现出类 似于蜂窝状的表面形貌, 与文献中报道的结果相
似 ${ }^{[16]}$ 。随着 $\mathrm{pH}$ 升高, 样品 S-pH6.7 展现出了褶皱状 的形貌, 且有少量团聚体出现。当电镀溶液 $\mathrm{pH}$ 达到 7.2 时, Co-S 薄膜呈现出纳米薄片状结构, 均匀覆盖 在 FTO 导电玻璃表面上(如图 1(c)所示)。而样品 S-pH7.6 表面上出现了大量团聚体。由此可见, 样品 S-pH7.2 的表面形貌更有利于提供较多的电催化活 性位点。

同时, 为了更加清晰观察 Co-S 薄膜的纳米薄片 状结构形貌, 在 $\mathrm{pH}=7.2$ 条件下对电沉积 30 圈制备 的 Co-S 薄膜进行 SEM 和 TEM 表征。从图 1(e)中 可明显看出由大量纳米薄片状结构堆积而形成的岛 状形貌, 这是长时间电沉积的结果。此 Co-S 薄膜经 剥离, 其 TEM 照片如图 1(f)所示。很显然, Co-S 薄 膜是由大量纳米薄片状结构组成, 这与 SEM 照片 相吻合。由此进一步证明, 样品 S-pH7.2 具有纳米 薄片状结构。为了分析 Co-S 薄膜中的元素分布, 图 1(g)给出了样品 S-pH7.2 的元素分布图。通过对 比发现, 钴元素和硫元素都均匀分布在 FTO 导电玻 璃表面, 且钴含量要高于硫含量。在样品 S-pH7.2 上任取三个区域, 进行元素含量分析, 发现钴含量 约是硫含量的 9 倍, 如图 1(h) 所示。由此可见, 通过
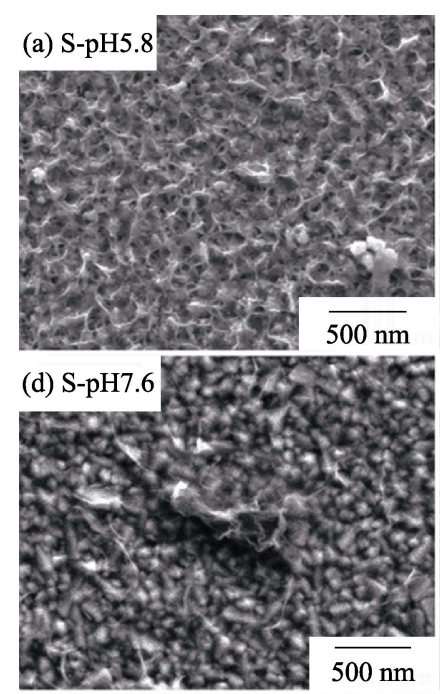

(g)

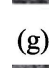

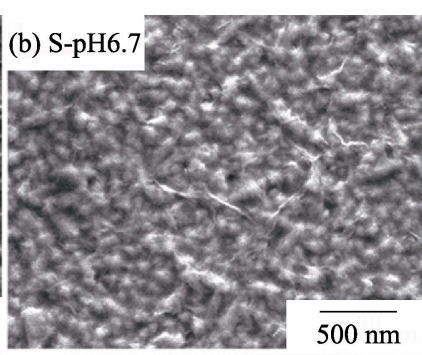

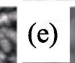

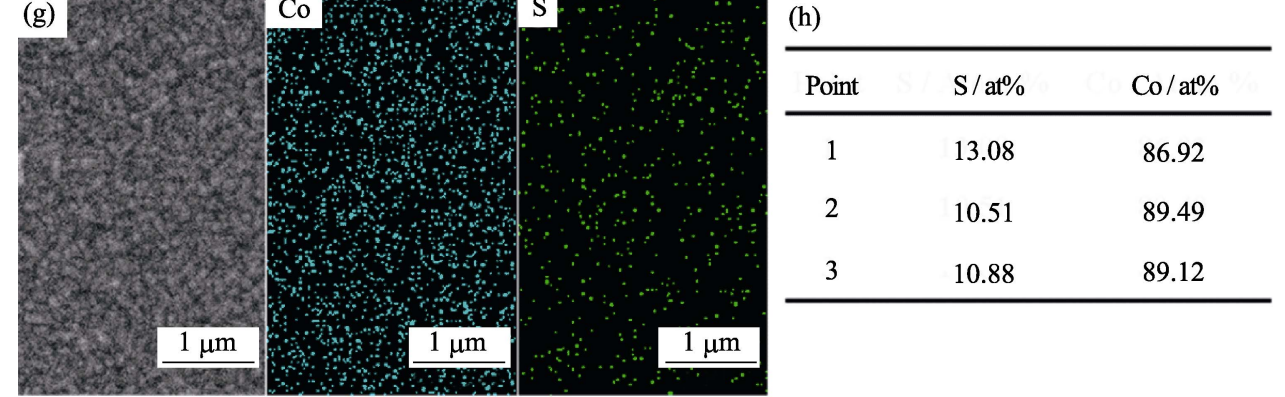

图 1 (a) (d) Co-S 薄膜的 SEM 照片; 在 $\mathrm{pH}=7.2$ 条件下, 电沉积 30 圈制备的 Co-S 薄膜 SEM (e)和 TEM (f)照片; 样品 S-pH7.2 的元素分布图(g)和元素含量百分比(h)

Fig. 1 (a-d) SEM images of Co-S films; (e) SEM and (f) TEM images of Co-S film under electrodeposition condition of pH 7.2 and 30 cycles; (g) The EDS mapping images and (h) element compositions of S-pH7.2 
调节电镀溶液的 $\mathrm{pH}$ 能有效调控 Co-S 薄膜的表面形 貌，从而制备出具有纳米薄片状结构的透明 Co-S 薄膜。

为了进一步确定 Co-S 薄膜的元素组成及价态, 以样品 S-pH7.2 为例, 进行 XPS 表征。图 2 是 Co2p 和 S2p 的 XPS 图谱。采用高斯拟合方法对 Co2p 和 S2p 图谱进行拟合。在图 2(a) Co2p 图谱中, 由自旋轨道耦合作用产生了一对特征峰, 以及两个卫星峰 (记为 Sat.)。这对特征峰的位置分别在 797.16 和 $781.11 \mathrm{eV}$, 分别归属于 $C 02 \mathrm{p}_{1 / 2}$ 和 Co2 $\mathrm{p}_{3 / 2}$, 对应于钴 基硫化物中 $\mathrm{Co}^{2+[6-7]}$ 。此外, 在 $783.13 \mathrm{eV}$ 处的特征 峰归属于 $\mathrm{Co}(\mathrm{OH})_{2}$, 可能是由于在电镀溶液中引入 氨水溶液而产生的杂质 ${ }^{[17-18]}$ 。在 S2p 图谱中, 隶属 于 $2 \mathrm{p}_{1 / 2}$ 和 $2 \mathrm{p}_{3 / 2}$ 的两个峰的位置分别在 164.02 和 $163.16 \mathrm{eV}$ ，对应于金属硫化物中 $\mathrm{S}$ 的特征峰 ${ }^{[6,19]}$ 。同 时, 168.54 和 $169.52 \mathrm{eV}$ 处的特征峰可能是由 S-O 产 生的 ${ }^{[6,19]}$ 。经分析可知, 样品 S-pH7.2 是由 Co 和 S 两种元素组成, 且与上述结论相吻合。

\subsection{DSC 光伏性能分析}

在硫化钴薄膜制备过程中, 电沉积时间对硫化 钴薄膜的电催化性能有着至关重要的影响 ${ }^{[12]}$ 。经上 述讨论可知, 当电镀溶液的 $\mathrm{pH}$ 达到 7.2 时, Co-S 薄
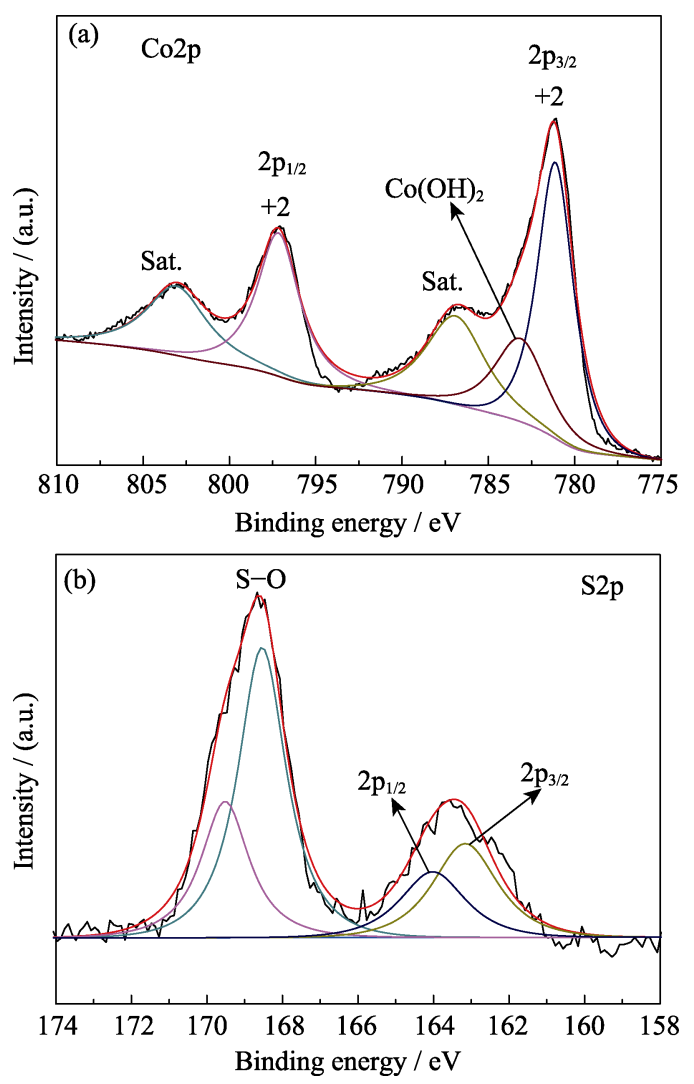

图 2 样品 S-pH7.2 的 XPS 图谱

Fig. 2 XPS spectra of S-pH7.2

(a) Co2p; (b) S2p
膜具有纳米薄片状结构, 拥有较多的催化活性位点, 有利于提高对电极的电催化活性 ${ }^{[20]}$ 。以此为基础, 研究电沉积圈数对基于 Co-S 对电极的 DSC 光伏性 能的影响。图 3(a) 是 DSC 的 $J-V$ 曲线, 其中把电沉 积圈数为 10、12、14 及 16 圈制备的 Co-S 薄膜分别 标记为 S-C10、S-C12、S-C14 和 S-C16。表 1 给出 了相关光伏性能参数。从表 1 中可知, 基于 S-C12 的 DSC 展现出了较高的能量转换效率 $(\eta=7.26 \%)$, 其中短路电流密度 $\left(J_{\mathrm{sc}}\right)$ 为 $18.47 \mathrm{~mA} / \mathrm{cm}^{2}$ 、开路电压 $\left(V_{\mathrm{oc}}\right)$ 为 $0.69 \mathrm{~V}$ 、填充因子 $(F F)$ 为 0.57 。相比较于铂 电极器件的电池效率 $\left(\eta=6.94 \%, J_{\mathrm{sc}}=15.94 \mathrm{~mA} / \mathrm{cm}^{2}\right.$ 、 $\left.V_{\mathrm{oc}}=0.67 \mathrm{~V} 、 F F=0.65\right), \mathrm{DSC}$ 的 $\eta$ 增加了 $4.6 \%$ 。随着 电沉积圈数增加, $J_{\mathrm{sc}}$ 减小, 可能是由于 Co-S 薄膜越 厚, 比表面积越小, 导电性越差, 不利于电子传输 与迁移 ${ }^{[12]}$ 。由此可知, 电沉积圈数经优化以后, 最 佳值为 12 圈。

采用以电沉积 12 圈为基础制备的样品 S-pH5.8、 S-pH6.7、S-pH7.2 和 S-pH7.6 作为对电极, 探讨 Co-S 薄膜表面形貌对 DSC 光伏性能的影响。图 3(b)是相 应 DSC 的 $J-V$ 曲线, 且对应光伏性能参数如表 1 所示。 经比较可知, $J_{\mathrm{sc}}$ 值大小顺序为 S-pH7.2 > S-pH6.7 > Pt $>$ S-pH5.8 > S-pH7.6。S-pH7.2 对电极的 $J_{\text {sc }}$ 最高, 可能是由于纳米薄片状结构拥有较大的比表面积, 从而获得较多的电催化活性位点, 有利于提高电荷 传输与迁移能力。而样品 S-pH5.8 呈现出类似于蜂 窝状结构, 样品 S-pH7.6 有大量团聚体, 都不利于 电荷的传输与迁移, 从而影响其电催化性能 ${ }^{[20]}$ 。由于 采用相同光阳极与电解液进行 DSC 的组装, 所以所 有 DSC 有相似的 $V_{\mathrm{oc}}$ 。然而, 更值得关注的是基于 Co-S 对电极的 DSC 表现出较小的 $F F$, 如表 1 所示。 这可能是由于 Co-S 薄膜的导电性较差, 或 Co-S 薄 膜中钴元素含量高, 硫化钴结晶度低, 致使串联电 阻变大, 从而引起 $F F$ 降低 ${ }^{[20]}$ 。因此, DSC 的 $\eta$ 大小 顺序为 S-pH7.2 > Pt > S-pH6.7 > S-pH5.8 > S-pH7.6。

从图 3(a) (b)和表 1 中明显看出, 电镀溶液的 $\mathrm{pH}$ 为 7.2、电沉积圈数为 12 圈制备的 Co-S 薄膜具 有优异的电催化性能, 由其构成的 DSC 拥有较高的 效率, 且高于基于铂电极的电池效率。在此最优条 件下, 分别组装 10 个 DSC, 其光伏性能参数的分布 图如图 3(c) 所示, $\eta 、 J_{\mathrm{sc}} 、 V_{\mathrm{oc}}$ 及 $F F$ 的平均值分别为 $7.18 \% 、 17.40 \mathrm{~mA} / \mathrm{cm}^{2} 、 0.69 \mathrm{~V}$ 及 0.60 。这充分说明 基于 S-pH7.2 的 DSC 具有很好的重复性。

\section{3 对电极电催化性能分析}

为了阐明 Co-S 对电极的电催化活性, 采用三电 极系统测试对电极的 $\mathrm{CV}$ 曲线, 如图 4 所示。从图 

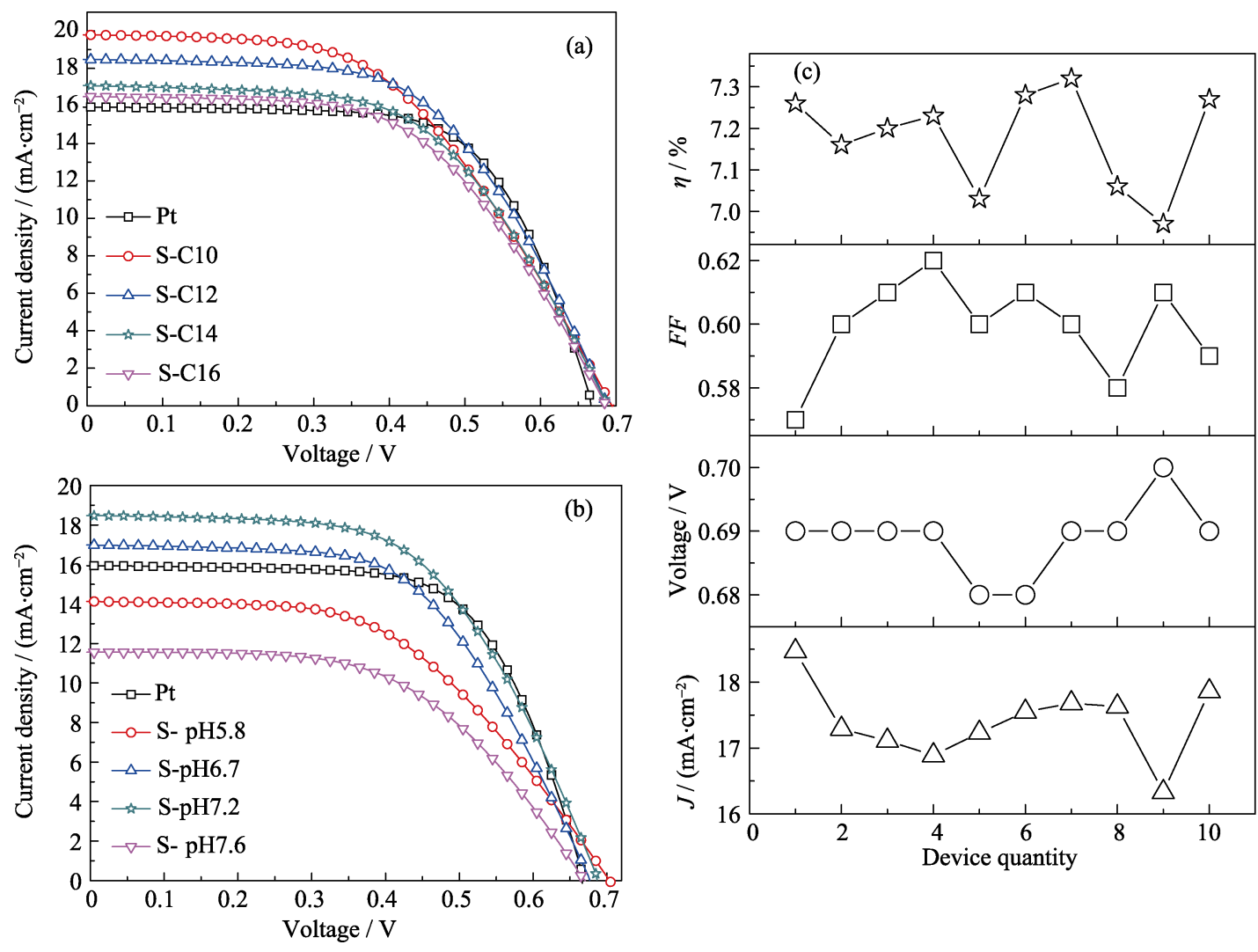

图 3 (a) (b) 基于 Co-S 对电极与铂电极的 DSC 的 $J-V$ 曲线和(c)基于 S-pH7.2 的 DSC 光伏性能参数分布图

Fig. 3 (a, b) $J-V$ curves of DSC based on Co-S and Pt Ces and (c) photovoltaic parameters of DSC based on S-pH7.2 as a function of device quantity

表 1 基于 Co-S 对电极与铂电极的 DSC 光伏性能参数 Table 1 Photovoltaic performance parameters of DSC based on Co-S and Pt Ces

\begin{tabular}{ccccc}
\hline $\mathrm{CE}$ & $J_{\mathrm{SC}} /\left(\mathrm{mA} \cdot \mathrm{cm}^{-2}\right)$ & $V_{\mathrm{OC}} / \mathrm{V}$ & $F F$ & $\eta / \%$ \\
\hline Pt & 15.94 & 0.67 & 0.65 & 6.94 \\
S-C10 & 19.78 & 0.69 & 0.51 & 6.96 \\
S-C12 & 18.47 & 0.69 & 0.57 & 7.26 \\
S-C14 & 17.11 & 0.69 & 0.56 & 6.61 \\
S-C16 & 16.52 & 0.69 & 0.55 & 6.27 \\
S-pH5.8 & 14.10 & 0.70 & 0.52 & 5.13 \\
S-pH6.7 & 16.96 & 0.68 & 0.56 & 6.46 \\
S-pH7.2 & 18.47 & 0.69 & 0.57 & 7.26 \\
S-pH7.6 & 11.56 & 0.67 & 0.54 & 4.18 \\
\hline
\end{tabular}

中可看出, 除了 S-pH7.6 对电极以外, 其余 Co-S 对 电极与铂电极均展现出了两对氧化还原峰。低电势 (左侧)与高电势 (右侧)氧化还原峰分别对应的氧化 还原反应为 $\mathrm{I}_{3}^{-}+2 \mathrm{e}^{-} \rightleftharpoons 3 \mathrm{I}^{-}$和 $3 \mathrm{I}_{2}+2 \mathrm{e}^{-} \rightleftharpoons 2 \mathrm{I}_{3}^{-[16]}$ 。考虑 到对电极的主要作用是将 $\mathrm{I}_{3}^{-}$催化还原成 $\mathrm{I}^{-}$, 则着重 于考察左侧的氧化还原峰。通过比较还原峰电流密 度 $\left(\left|J_{\mathrm{Red}}\right|\right)$ 、氧化峰与还原峰间距 $\left(E_{\mathrm{pp}}\right)$ 两个参数能有 效评价对电极的电催化活性。其中, $\mid J_{\text {Red }}$ 值越大, $E_{\mathrm{pp}}$ 值越小, 则说明对电极的电催化活性越好。通过对 比发现, S-pH7.2 对电极的 $\left|J_{\text {Red }}\right|$ 值与铂电极近似,

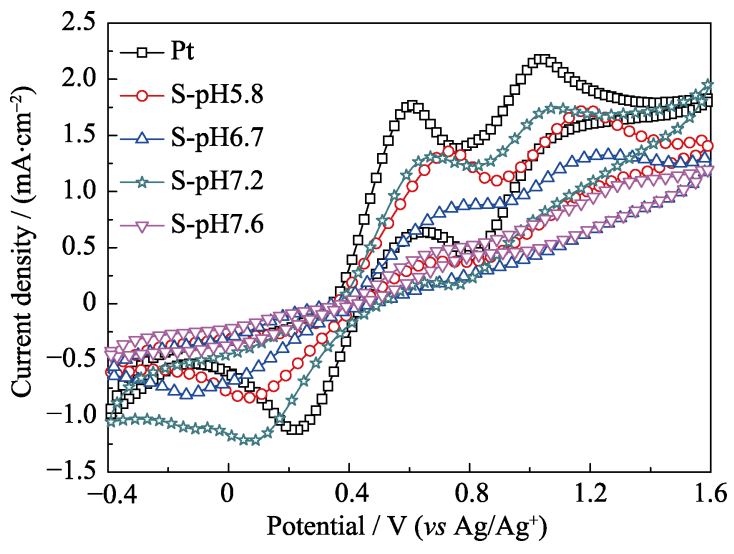

图 $4 \mathrm{Co}-\mathrm{S}$ 对电极与铂电极的 $\mathrm{CV}$ 曲线

Fig. 4 CV curves of Co-S and Pt CEs

S-pH7.2 对电极的 $E_{\mathrm{pp}}$ 值略大于铂电极。这就说明 S-pH7.2 对电极对 $\mathrm{I}_{3}^{-}$的电催化活性在一定程度上与 铂电极相当。

采用电化学阻抗谱分析对电极中电荷传输能力, 进一步验证上述结论。图 5 是由完全相同对电极构 成的对称电池的 EIS 奈奎斯特图, 其中图 5(a)的插 图是等效模拟电路图。通过采用 ZView 软件进行模 拟，相关参数如表 2 所示。从图 5 中可明显看出，所 有奈奎斯特图均展现出了两个半圆, 且模拟值与实 验值吻合较好。根据模拟电路图, 串联电阻 $\left(R_{\mathrm{S}}\right)$ 代表 

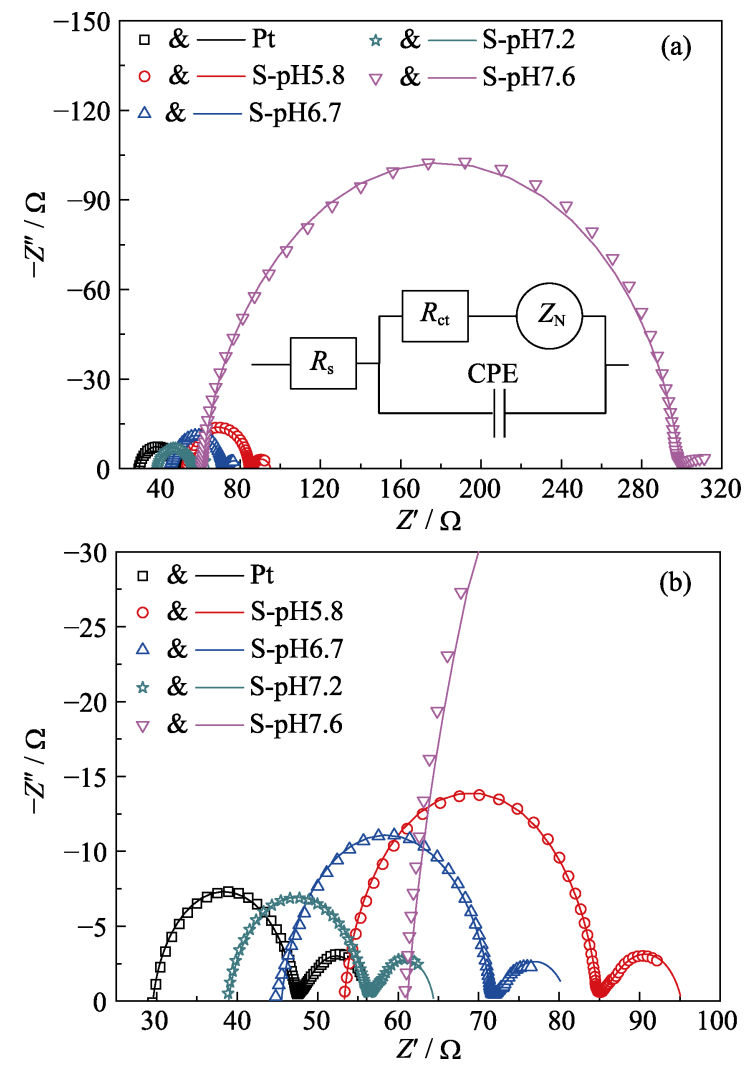

图 5 对称电池的 EIS 奈奎斯特图, (a)中的插图是等效电路图 Fig. 5 Nyquist plots of EIS for symmetrical cells with the inset in (a) showing the equivalent circuit

The symbols represent experiment data, and the solid lines express fit results for EIS data.

表 2 Co-S 对电极与铂电极的 EIS 拟合参数 Table 2 Fitting parameters of EIS for Co-S and Pt Ces

\begin{tabular}{crcccc}
\hline $\mathrm{CE} s$ & \multicolumn{1}{c}{$\mathrm{Pt}$} & $\mathrm{S}-\mathrm{pH} 5.8$ & $\mathrm{~S}-\mathrm{pH} 6.7$ & $\mathrm{~S}-\mathrm{pH} 7.2$ & $\mathrm{~S}-\mathrm{pH} 7.6$ \\
\hline$R_{\mathrm{S}} / \Omega$ & 29.55 & 53.32 & 45.52 & 38.95 & 61.13 \\
$R_{\mathrm{ct}} / \Omega$ & 17.56 & 31.21 & 25.86 & 16.98 & 237.10 \\
$Z_{\mathrm{N}} / \Omega$ & 9.01 & 10.67 & 9.69 & 8.51 & 20.21 \\
\hline
\end{tabular}

传输电阻、材料体电阻和接触电阻之和; 电荷传输 电阻 $\left(R_{\mathrm{ct}}\right)$ 代表对电极/电解质的界面特性; 能斯特扩 散阻抗 $\left(Z_{\mathrm{N}}\right)$ 代表电解质中 $\mathrm{I}^{-} / \mathrm{I}_{3}^{-}$氧化还原对的能斯特 扩散过程。从表 2 中可知, Co-S 对电极的 $R_{\mathrm{S}}$ 均大于 铂电极。这可能是 Co-S 对电极的 $F F$ 要小于铂电极 的原因 ${ }^{[21]}$ 。一般情况下, 电荷传输能力体现在 $R_{\mathrm{ct}}$ 和 $Z_{\mathrm{N}}$ 两个参数上。 $R_{\mathrm{ct}}$ 和 $Z_{\mathrm{N}}$ 越小, 意味着电荷传输 能力越强, 则对电极电催化性能越好。通过比较发 现, $R_{\mathrm{ct}}$ 和 $Z_{\mathrm{N}}$ 值大小顺序为 S-pH7.2 $<\mathrm{Pt}<\mathrm{S}-\mathrm{pH} 6.7<$ S-pH5.8 $<$ S-pH7.6。其中, S-pH7.6 对电极的 $R_{\mathrm{ct}}$ 远远 大于其他对电极, 而对应 DSC 的 $F F$ 与其他 DSC 相 当。这一实验现象类似于已有的报导 ${ }^{[16]}$ 。可能是因 为在基于 S-pH7.6 对电极的 DSC 中, 对电极对 $\mathrm{I}_{3}^{-}$的 电催化活性较差, 染料分子激发态的密度小, 产生 了较小的 $J_{\mathrm{sc}}$ 使得在光阳极/电解液界面上电荷的复
合概率减小, 从而引起 $F F$ 降低。因此, EIS 分析结 果也表明 S-pH7.2 对电极的电催化活性与铂电极相 当。由此可见, $J-V$ 曲线、 CV 曲线和 EIS 奈奎斯特 图分析结果相互印证, 均表明纳米薄片状结构的 Co-S 对电极具有优异的电催化活性, 由其构成的 DSC 拥有良好的光伏性能。

\section{3 结论}

采用一种简单的反向恒压电沉积法在 FTO 导电 玻璃上制备透明硫化钴薄膜; 经电镀溶液 $\mathrm{pH}$ 及电沉 积圈数优化, 发现在 $\mathrm{pH}=7.2$ 条件下电沉积 12 圈能有 效构建出纳米薄片状结构的硫化钴薄膜。电化学测 试结果表明硫化钴薄膜表面形貌影响其电荷传输能 力, 其中具有纳米薄片状结构的硫化钴对电极展现 出了优异的电催化活性。同时, 参照铂电极器件的电 池效率(6.94\%), 由其组装的染料敏化太阳能电池呈 现出较高的能量转换效率(7.26\%), 且 10 个电池的平 均效率为 $7.18 \%$ 。相关实验结果为进一步设计高效、 廉价、透明的硫化钴对电极提供了思路。

\section{参考文献:}

[1] CHEN X, LI C, GRATZEL M, et al. Nanomaterials for renewable energy production and storage. Chem. Soc. Rev., 2012, 41(23): 7909-7937.

[2] CHEN G, SEO J, YANG C, et al. Nanochemistry and nanomaterials for photovoltaics. Chem. Soc. Rev., 2013, 42(21): 8304-8338.

[3] FREITAG M, TEUSCHER J, SAYGILI Y, et al. Dye-sensitized solar cells for efficient power generation under ambient lighting. Nat. Photon., 2017, 11(6): 372-378.

[4] JIANG Q S, PAN K, LEE C S, et al. Cobalt-nickel based ternary selenides as high-efficiency counter electrode materials for dye-sensitized solar cells. Electrochim. Acta, 2017, 235: 672-679.

[5] YUN S N, LUND P D, HINSCH A. Stability assessment of alternative platinum free counter electrodes for dye-sensitized solar cells. Energy Environ Sci., 2015, 8(12): 3495-3514.

[6] YUAN H, JIAO Q, LIU J, et al. Ultrathin-walled Co9S8 nanotube/reduced graphene oxide composite as an efficient electrocatalyst for the reduction of triiodide. J. Power Sources, 2016, 336: 132-142.

[7] LUO F, LI J, YUAN H, et al. Rapid synthesis of three-dimensional flower-like cobalt sulfide hierarchitectures by microwave assisted heating method for high-performance supercapacitors. Electrochim. Acta, 2014, 123: 183-189.

[8] MIAO X, PAN K, WANG G, et al. Well-dispersed CoS nanoparticles on a functionalized graphene nanosheet surface: a counter electrode of dye-sensitized solar cells. Chem. Eur. J., 2014, 20(2): 474-482.

[9] LIN J Y, LIAO J H, WEI T C. Honeycomb-like CoS counter elec- 
trodes for transparent dye-sensitized solar cells. Electrochem. Solid-State Lett., 2011, 14(4): D41-D44.

[10] JIA J, WU J, DONG J, et al. Influence of deposition voltage of cobalt diselenide preparation on the film quality and the performance of dye-sensitized solar cells. Sol. Energy, 2017, 151: 61-67.

[11] WANG M K, ANGHEL A M, MARSAN B, et al. CoS supersedes $\mathrm{Pt}$ as efficient electrocatalyst for triiodide reduction in dye-sensitized solar cells. J. Am. Chem. Soc., 2009, 131(44): 15976-15977.

[12] SWAMI S K, CHATURVEDI N, KUMAR A, et al. Investigation of electrodeposited cobalt sulfide counter electrodes and their application in next-generation dye sensitized solar cells featuring organic dyes and cobalt-based redox electrolytes. J. Power Sources, 2015, 275: 80-89.

[13] SUN H, QIN D, HUANG S, et al. Dye-sensitized solar cells with NiS counter electrodes electrodeposited by a potential reversal technique. Energy Environ. Sci., 2011, 4(8): 2630-2637.

[14] LIN J Y, TSAI Y T, TAI S Y, et al. Pulse-reversal deposition of cobalt sulfide thin film as a counter electrode for dye-sensitized solar cells. J. Electrochem. Soc., 2013, 160(2): D46-D52.

[15] JIANG Q S, GAO J, YI L, et al. Enhanced performance of dye-sensitized solar cells based on $\mathrm{P} 25 / \mathrm{Ta}_{2} \mathrm{O}_{5}$ composite films.
Appl. Phys. A, 2016, 122(4): 442.

[16] HUO J, WU J, ZHENG M, et al. Effect of ammonia on electrodeposition of cobalt sulfide and nickel sulfide counter electrodes for dye-sensitized solar cells. Electrochim. Acta, 2015, 180: 574-580.

[17] LIN J Y, LIAO J H, CHOU S W. Cathodic electrodeposition of highly porous cobalt sulfide counter electrodes for dye-sensitized solar cells. Electrochim. Acta, 2011, 56(24): 8818-8826.

[18] LIU T, LIANG Y, LIU Q, et al. Electrodeposition of cobalt-sulfide nanosheets film as an efficient electrocatalyst for oxygen evolution reaction. Electrochem. Commun., 2015, 60: 92-96.

[19] CUI X, XIE Z, WANG Y. Novel $\mathrm{CoS}_{2}$ embedded carbon nanocages by direct sulfurizing metal-organic frameworks for dye-sensitized solar cells. Nanoscale, 2016, 8(23): 11984-11992.

[20] TAI S Y, CHANG C F, LIU W C, et al. Optically transparent counter electrode for dye-sensitized solar cells based on cobalt sulfide nanosheet arrays. Electrochim. Acta, 2013, 107: 66-70.

[21] BAO C, LI F, WANG J, et al. One-pot solvothermal in situ growth of 1D single-crystalline NiSe on Ni foil as efficient and stable transparent conductive oxide free counter electrodes for dye-sensitized solar cells. ACS Appl. Mater. Interfaces, 2016, 8(48): 32788-32796 